\title{
LOS KAOLINES DE LA HACIENDA DE YEXTHÓ
}

\author{
por José G. Aguilera.
}

El terreno de la Hacienda de Yexthó está formado de rocas eruptivas terciarias, y con los productos de la alteración de estas rocas está rellenado parte del fondo del estrecho valle en que corre el río de San Juan del Río, en cuya ribera derecha está el caserío de la Hacienda á una altura de 1,700 metros sobre el nivel del mal y casi en la línea divisoria de los Estados de Hidalgo y Querétaro y en jurisdicción todavía del primero de dichos Estados.

Los terrenos de la Hacienda forman parte de la extensa interesante región volcánica que se extiende desde cerca de Huichapan por un lado, hasta Querétaro, por el otro lado. A los diferentes paroxismos de la actividad volcánica de fecha relativamente reciente y de los cuales hay en la actualidad numerosas manifestaciones, débese lo quebrado del suelo de la Hacienda de Yexthó, cuya topografía se reduce á un valle estrecho, abierto por erosión entre corrientes de lava y cerros volcánicos destruídos, que se ensancha en algunos tramos.

Las rocas eruptivas son: rhyolita y basalto. La sucesión de estas rocas, ó sea el orden de su aparición es el que mismo en que están enumeradas. La roca más antigua, la rhyolita., hizo su aparición bajo la forma de domas por acumulación de la roca fundida encima de las chimeneas de salida que quedaron cubiertas por ella y por corrientes que escurrían siguiendo el declive del terreno, sobre las calizas compactas cretáceas que se extendían en toda esa comarca, y las cuales plegadas, dislocadas y fracturadas habían estado sujetas á la erosión desde fines del Cretácico hasta principios del Plioceno en que aparecieron las rhyolitas. Después de un período de reposo que representa casi todo el Plioceno, al terminar éste, la actividad volcánica se manifiesta de nuevo con bastante energía y da origen á conos basálticos y corrientes de basalto, separadas por capas de brechas, tobas y arenas, que se alternan varias veces, y corresponden respectiva 
mente á erupciones lávicas tranquilas y á erupciones lodosas y brechógenas, en parte explosivas. Este último período de actividad no ha terminado todavía y de él son las últimas y débiles manifestaciones los numerosos manantiales termales que se encuentran en la región, preferentemente en terrenos de Pathé, Hacienda colindante con la de Yexthó.

La historia geológica del suelo de Yexthó se resume, por lo que respecta á la formación de los depósitos de Kaolin, en un período de erupciones, período de construcción del relieve del terreno, que duró todo el Plioceno, y un periodo de erosión ó destrucción que le siguió y se extiende hasta nuestros días, que ha modelado el relieve, desgastándolo sin cesar, para labrar el valle por el cual circula el río en la actualidad.

El basalto de las corrientes y conos volcánicos de los terrenos de Yexthó está subdividido en numerosas lajas delgadas que le dan el aspecto á dicha roca de un depósito de pizarra. Esta división en lajas del basalto, ha permitido su rápida alteración, que en algunos lugares está sumamente avanzada, transformándose el basalto entonces en arcillas impuras, barros contemporáneos.

En las corrientes de basalto existen numerosas fracturas que atraviesan su masa entrecruzándose en redes y por cuyas fracturas, que han sido motivadas por la contracción de volumen de la roca al pasar del estado fluido al sólido, han circulado aguas termales que las han tapizado de arcillas más menos puras, sulfato de cal, cuarzo y carbonato de cal, que las aguas traían en disolución y en su salida, al enfriarse con el contacto del aire, y por la diminución de presión, abandonan en las paredes de la fractura, hasta llegar á obstruirse ellas mismas con sus depósitos estos canales de circulación.

Además de estas redes de fracturas de pequeñas dimensiones aunque numerosas, existen otras poderosas que se manifiestan en la superficie del terreno por tramos de más de 200 metros de largo. Estas fracturas, sumamente importantes por su contenido que les da un valor industrial de alguna importancia, siguen la dirección media N. S., con echado de $80^{\circ}$ al E., haciendo al rumbo algunas ondulaciones, de manera que su curso no es una línea recta, sino una línea ligeramente sinuosa, y sufren también, naturalmente de acuerdo con las variaciones en el rumbo, modificaciones en el echado. Estas fracturas, rellenadas por arcilla, yeso y cuarzo, como elementos esenciales, forman las vetas de Kaolín que se explotan en la Hacienda de Yexthó. 
Los criaderos principales explotados son: los de Mothó, Santa Rosa, El Có y La Salitrera. La mina del Mothó á 1,670 metros de altura sobre el nivel del mar, está abierta en una veta con rumbo $\mathrm{N}$. S. echado de $80^{\circ}$ al $\mathrm{E}$. La roca en que arma esta veta es basalto-hojoso sumamente alterado. La veta sinuosa en su curso, tiene estrechamientos y ensanchamientos alternativos, llegando en estos á tener dos metros de anchura; el material que rellena la veta es de distinta coloración y pureza en diferentes tramos de su curso. En la veta, por uno de los respaldos sale agua poco caliente, $25^{\circ}$ y sobre la misma veta hay un manantial ligeramente sulfuroso que surge cerca del río y se utiliza para unos baños; la de temperatura de este manantial es de $31^{\circ}$. En el basalto que forman los respaldos, éstos se ven tapizados por pyrita de formación reciente.

La mina de Santa Rosa está abierta en una veta que, en el tramo más explotado, tiene $1 \mathrm{~m}$. 70 de potencia, llevando en la parte media de su espesor un caballo de $75 \mathrm{~cm}$. Corre una veta con rumbo N. S., desviándose en tramo $10^{\circ}$ ó $15^{\circ}$ unas veces al E. y otras al W.; es casi vertical, haciendo el cuerpo de la veta ondulaciones al echado. La veta está compuesta de zonas de concreción de kaolin, cuarzo blanco, y cerca de los respaldos, yeso fibroso. El kaolin es de colores blanco y rosado el más puro, y amarillento el de menor calidad. El kaolin de mejor calidad viene en pequeñas bolsas dentro de las zonas de kaolin y se distingue del menos puro además de su color, que hemos dicho que es blanco rosado, por ser más blando y ligeramente untuoso, caracteres que facilitan su separación ó pepena en la mina á los trabajadores. En el cuerpo de la veta se encuentran pequeños blocks de rhyolita alterada; los cuales están envueltos por las concreciones de kaolin.

La mina del Có se abrió en una costra de kaolin que reviste á una corriente de rhyolita. La costra de kaolin es bastante homogénea, casi horizontal y de espesor aproximadamente de $2 \mathrm{~m}$. La rhyolita alterada se presenta en la inmediación del criadero de kaolin del Có, en capas de corriente con rumbo NW-SW., y echado de $75^{\circ}$ al NE., que en algunos puntos del criadero vienen inmediatamente debajo del kaolin, que está cubierto en algunos tramos por una costra de yeso.

En la mina La Salitrera, el kaolin, como en la anterior, viene en costra, que forma una especie de capa, que cubre directamente á una corriente de rhyolita compacta, y á su vez cubierto por una co 
rriente de basalto en lajas. El respaldo bajo formado por la rhyolita muestra esta roca en pastes ampollosa, y se ven en ella todos los grados de transición entre la rhyolita no alterada y el kaolin; éste lleva cuarzo libre, unas veces en granos y otras en hojitas ó láminas muy delgadas, residuo de los cristales de cuarzo primitivo de la rhyolita que ha sido casi en su totalidad disuelto por el agua.

Las minas citadas son los principales puntos de explotación de los criaderos de kaolin, y los trabajos, que son todos a cielo abierto, son muy superficiales y desordenados; y se comprende que sólo se han preocupado de escarbar en los tramos de las vetas, en que el mineral era de mejor clase, y aun en estos tramos se ha hecho en partes una verdadera disección de la veta, tratando naturalmente de seguir en las zonas de concreción la del kaolin más puro.

La génesis de estos criaderos puede explicarse de la siguiente manera: las poderosas erupciones rhyolíticas que ya hemos dicho al principio de este informe, tuvieron lugar en toda esta comarca, formaron un suelo de relieve poco accidentado, por haber venido estas rocas en corrientes que, siguiendo las pendientes existentes entonces en el suelo, rellenaron en parte hondonadas y depresiones, tendiendo á darles una pendiente general uniforme; este periodo de actividad bastante prolongado y enérgico cubrió pues la superficie del terreno con capas de rocas de consistencia diferente, unas compactas, resistentes, que vienen en la parte inferior, y las otras brechiformes menos resistentes, formadas en parte por el escurrimiento de la roca fluida, que corriendo caliente encontraba roca ya enfriada, agrietada y reventada por la contracción de volumen consiguiente al paso del estado fluido al sólido durante su enfriamiento, y escurría, penetrando por todas la soluciones de continuidad de la masa de la roca llenándolas y cimentando la roca al solidificarse, ó bien el extremo ó frente de la corriente de la roca en fusión arrastraba, envolviendo y cimentando, todos los fragmentos, cantos y pequeños blocks que encontraba á su paso, y finalmente, las erupciones daban ellas mismas origen á una brecha.

Siguió á este período de erupción rhyolítica, que está en relación con una de las fases principales del movimiento orogénico de esta porción del país, otro período de actividad volcánica, bastante intenso, pero de energía menor que el rhyolitico, que abrazó una extensión superficial más pequeña; es el periodo de erupción basáltica que siguió al último poderoso esfuerzo orogénico, y durante cuyo 
período, en los lugares de menor resistencia, se abrió paso el basalto, formando domas y conos volcánicos con cráteres, por los cuales se sucedían erupciones de lavas y erupciones lodosas ó de tobas. La topografía de esta región que con el último movimiento orogénico perdía la uniformidad que en parte le habían dado las erupciones rhyoliticas se volvió más irregular y fragosa, y alcanzó, con formación de las montañas basálticas, su mayor grado de complicación y de elevación.

Los conos basálticos cubren en la Hda. de Yexthó á las rhyolitas á través de las cuales se han abierto las chimeneas que han dado salida al basalto, alterando, á distancias variables, que están en relación con la energía de las erupciones basálticas de cada lugar, la roca por cuya masa, en las partes fracturadas y permeables, circulaban las aguas calientes de las fumarolas, que sucedieron á las erupciones basálticas, formando zonas en la proximidad inmediata ó en la periferia de los macizos basálticos.

Una vez formados los macizos basálticos y á consecuencia de los movimientos que ultimaron definitivamente el relieve del terreno y con los cuales terminaron los paroxismos volcánicos de esta región se produjeron fracturas poderosas en el terreno que responden á la dirección de las líneas tectónicas de esta parte del país, ó sea N.-S. con desviaciones ya al E. ya al W. por las cuales ascendieron las aguas sobrecalentadas y sujetas a tensión, que habiendo desempeñado un papel importantísimo en la erupción del basalto, al disminuir la energía volcánica, habían quedado contenidas en la roca semifluida profunda, y que al abrirse estas grietas ó fracturas encontraban fácil salida, convirtiéndolas en canales de circulación, iniciándose además allí un ciclo de circulación que comienza con la penetración á profundidad en las rocas de las aguas de lluvia, hasta llegar á roca caliente, que convierte el líquido en vapor, comienza entonces un ascenso durante el cual transporta mecánicamente y al estado de disolución los elementos constitutivos de la rhyolita para abandonarlos á medida que su energía de transporte mecánico y químico se debilita en las fracturas del terreno, en su camino hacia la superficie.

La rhyolita que como todas las rocas cristalinas es un silicato de alumina complexo, que bajo la acción del agua caliente ya sea magmática ya meteórica en su vadose, queda sometida á una alteración gradual, que cuando las relaciones que en la roca se verifican han tenido el tiempo bastante para ser completas, resulta la desaparición total de los álcalis de la roca, que han sido transportados 
por el agua; los metales alcalino-terrosos disueltos también cuando ha habido ácido carbónico en exceso, han sido en seguida precipitados en las cavidades y vacíos de la roca en donde el ácido carbónico se evapora. Los productos menos solubles: la sílice y alúmina parecen enriquecerse juntos al principio y después prolongándose la acción disolvente local la siliza también es transportada para ser depositada igualmente en las fracturas y cavidades de la roca basáltica, al disminuir la temperatura y la presión del agua, y queda al fin sílice combinada á la alúmina en el Kaolin ó arcilla, con tendencias á alcanzar la más completa transformación en siliza y beanxita, allí donde la roca llegue al último grado de alteración y en el resto de su masa se encontrarán yacimientos de Kaolin, arcilla mezclada de arena cuarzosa con restos de feldespatos imperfectamente kaolinizados ó con venillas de cuarzo ó pedernal.

De esta manera es como nos explicamos la formación de estos depósitos de kaolin en basalto, condiciones de yacimiento por primera vez descritas, tanto por la naturaleza de la roca en que arman los criaderos, como por la edad y naturaleza de estos. En la Salitrera y la mina del Có las relaciones genéticas de la rhyolita con el kaolin son evidentes: allí se ve el depósito de kaolin en la superficie de contacto de la rhyolita y el basalto, formando la primera el respaldo bajo y el último el respaldo alto del criadero; y el kaolin, siguiendo las irregularidades de la superficie de rhyolita. Esta está alterada en su masa, presentando todos los grados de descomposición hasta llegar al último extremo, indicando que ha sido en esta roca por su porosidad que se ha verificado la circulación del agua caliente que ha producido el kaolin, que allí se encuentra revuelto con el cuarzo, sin estar separado en zonas concrecionadas, como indicando que no ha habido transporte de material por aguas procedente de puntos más ó menos distantes, sino que la alteración in situ bajo la acción disolvente y prolongada del agua ha dejado allí parte insoluble de la roca, llevando el agua para abandonarlas en la masa de basalto que viene encima substancias solubles.

En la mina del Có parece haber habido, además de la circulación del agua caliente que produjo la alteración in situ de la rhyolita, dando origen á la zona kaolinizada en el contacto de la rhyolita y el basalto, un periodo de circulación de agua menos caliente cuya circulación se hacía por entre el depósito de kaolin y el basalto, durante el cual se formó la capita de yeso cristalizado que cubre al kaolin. 
Dada la poca solubilidad del sulfato de cal en el agua, hay que aceptar que ésta venía entonces de lejos, cargándose de sulfato para alcanzar su punto de saturación en este depósito, á favor de la diminución de presión y temperatura.

En la mina de Santa Rosa y en la del Mothó y en todas las otras vetas, la formación ha sido algo diferente si bien reconociendo el mismo origen, En estos criaderos las aguas, después de circular por un trayecto más ó menos largo á través de las rhyolitas, circulaban por éstas con fuerza bastante para transportar en suspensión los silicatos de alúmina insolubles; los cuales iban abandonando gradualmente en el interior de las fracturas, á medida que perdían energía dinámica, ó de transporte, y así iban formando zonas de kaolin más ó menos puros en diversos tramos de su trayecto; variaciones en la temperatura de el agua, y venidas de aguas más lejanas ó con menor presión, aunque cercanas, llegaban á las fracturas ó vetas desprovistas de material en suspensión, trayendo solamente su carga química ó sea de material en disolución, el cual iban abandonando gradualmente, de acuerdo con la diminución de temperatura y de presión, que hacían que el agua fuese alcanzando el grado de saturación necesario para la cristalización sucesiva de alguno de los elementos que traía en disolución, y así cada una formaba una zona de composición diferente en la veta. La misma agua que en la profundidad abandonaba en la veta kaolin, á mayor altura y en el mismo plano vertical tenía que depositar los elementos disueltos, en orden inverso de su solubilidad, es decir primero el menos soluble y al final el más soluble. Así pues, de esperarse que en la veta las zonas de concreción, ni se conserven constantes en su composición siguiéndolas á profundidad, ni tampoco siguiéndolas rumbo, sino que tanto en el sentido horizontal como en el vertical y á distancias variables para cada zona, el espesor de estas disminuya en cuña hasta ser reemplazada por otra zona de composición diferente.

Explicada de esta manera la génesis de estos depósitos de kaolin se comprende fácilmente que formados de abajo á arriba se puede contar con que se prolongan á profundidad, los que están situados en fracturas en el basalto hasta encontrar la rhyolita que viene debajo, que ha suministrado el material para el relleno de las fracturas, es decir, el espesor aproximado de las corrientes de basalto, y para los depósitos que están en el contacto de la rhyolita y el basalto hasta donde el aumento de la temperatura con la profundidad 
lo permitan, pues que las rocas profundas están aquí muy calientes y lo prueban los manantiales termales numerosos de la localidad, que deben su temperatura, no á la gran profundidad de que provienen, sino más bien á la alta temperatura en que se encuentran las rocas de los macizos volcánicos, relativamente recientes, que se encuentran en su periodo de enfriamiento, acercándose á su extinción probablemente definitiva, quiero decir con esto, que el agua de los manantiales termales es el agua lluvia que penetra á cierta profundidad en su circulación descendente ó vadose, en la cual atraviesan las rocas volcánicas que están todavía bastante calientes para llevar el agua á la temperatura de ebullición, y en ese estado, y bajo la tensión del vapor de agua desarrollado, una parte del agua sobrecalentada es levantada por las rendijas y oquedades más ó menos grandes de las rocas hasta la superficie con una temperatura muy vecina á la de ebullición.

Como por otra parte los criaderos en la superficie tienen dimensiones considerables; pues algunos tienen más de doscientos metros de largo, esta circunstancia unida á la anchura media de un metro y á la constancia del criadero hasta una profundidad regular, aseguran la existencia en ellos de una cantidad de kaolin bastante considerable suficiente para sostener su explotación por varios años.

La aplicación que se puede dar á esta substancia depende de su composición y el análisis varias muestras hecho en el Laboratorio de Química del Instituto Geológico Nacional por los Señores F. Roel, V. von Vigier y C. Castro, nos da los siguientes resultados:

Có. Santa Rosa. Mothó. Salitrera.

$\begin{array}{lrrrc} & \text { Có. } & \text { Santa Rosa. } & \text { Mothó. } & \text { Salitrera. } \\ & - & - & - & - \\ \mathrm{H}_{2} \mathrm{O} \text { á 105 } & 2.22 & 13.14 & 1.82 & 4.65 \% \\ \mathrm{H}_{2} \mathrm{O} \text { al rojo } & 12.97 & 7.97 & 5.01 & 2.29 \\ \mathrm{Si} \mathrm{O}_{2} & 43.22 & 55.46 & 59.51 & 80.79 \\ \mathrm{CO} 2 & & & & \begin{array}{c}\text { huellas } \\ \mathrm{P}_{2} \mathrm{O}_{5}\end{array} \\ \mathrm{Al}_{2} \mathrm{O}_{3} & 35.70 & 18.52 & 31.60 & 0.71 \\ \mathrm{Fe}_{2} \mathrm{O}_{3} & 0.56 & 3.44 & 1.11 & 1.29 \\ \mathrm{Ca} \mathrm{O} & 2.58 & \text { huellas } & 0.50 & 0.60 \\ \mathrm{Mg} \mathrm{O} & 0.77 & 1.54 & 0.04 & 0.70 \\ \mathrm{~K}_{2} \mathrm{O} & 2.25 & ---- & 0.01 & 0.21 \\ \mathrm{Na}_{2} \mathrm{O} & 0.62 & --- & 1.01 & 0.18 \\ & - & - & - & - \\ & 100.92 & 100.7 & 100.61 & 100.01\end{array}$


Aunque de la composición química no se pueden deducir de manera segura las calidades de porcelana fabricada con una arcilla, sirve aquella generalmente para conocer la existencia y proporción de los elementos que la perjudican; y así, con este convencimiento, buscar la manera de sustraerlos, ó neutralizar sus efectos por medio de revolturas con otras arcillas, lavados, etc. Así, la cal aumenta la fusibilidad de la arcilla por un lado y por otro neutraliza la coloración que la presencia del fierro puede dar á la arcilla; si se encuentra en proproción pequeña no le puede considera como nociva pero en cantidad considerable es muy perjudicial. La magnesia obra de la misma manera que la cal: aumenta la fusibilidad, disminuye la contracción de volumen de la arcilla y neutraliza la coloración del fierro. La potasa y la sosa tienden a aumentar la fusibilidad de la arcilla como el fierro, la cal y la magnesia. El fierro es perjudicial además por la coloración que da á la porcelana, y de sus proporciones y de su estado de oxidación depende la aplicación que se debe dar á la arcilla. La potasa es el elemento más perjudicial y cuando se encuentra en pequeña proporción produce una vitrificación incipiente de la arcilla que la hace sonora, propiedad que utilizan los comerciantes para su venta.

Comparando los análisis, se ve que la arcilla de la mina El Có tiene mayor proporción de potasa, sin que ésta llegue á un término perjudicial, convendrá sin embargo lavar esta arcilla antes de utilizarla sola ó en revoltura con otras de la misma ó diferente localidad.

La composición de estas arcillas, según el análisis corresponde á muchas de las buenas arcillas empleadas para la fabricación de la porcelana en los Estados Unidos y en Francia. Revolviendo estas arcillas con otras y beneficiándolas para quitarle la potasa cuando ésta venga en cantidad considerable, se podría fabricar muy buena porcelana.

La abundancia de las arcillas, la situación de los criaderos cerca del río donde se puede aprovechar una pequeña caída para la molienda y mezcla de las arcillas, la distancia relativamente corta. 18 á 20 k. de la Estación San francisco del F. C. Nacional y las condiciones del terreno sumamente favorables para la construcción de una vía Decanville de Yexthó á San Francisco, hacen que la explotación de estas arcillas tan cercanas á la capital sea un negocio de éxito seguro, siempre que sean utilizadas por operarios diestros en la fabricación de la porcelana. 